\title{
MICHAEL DICK
}

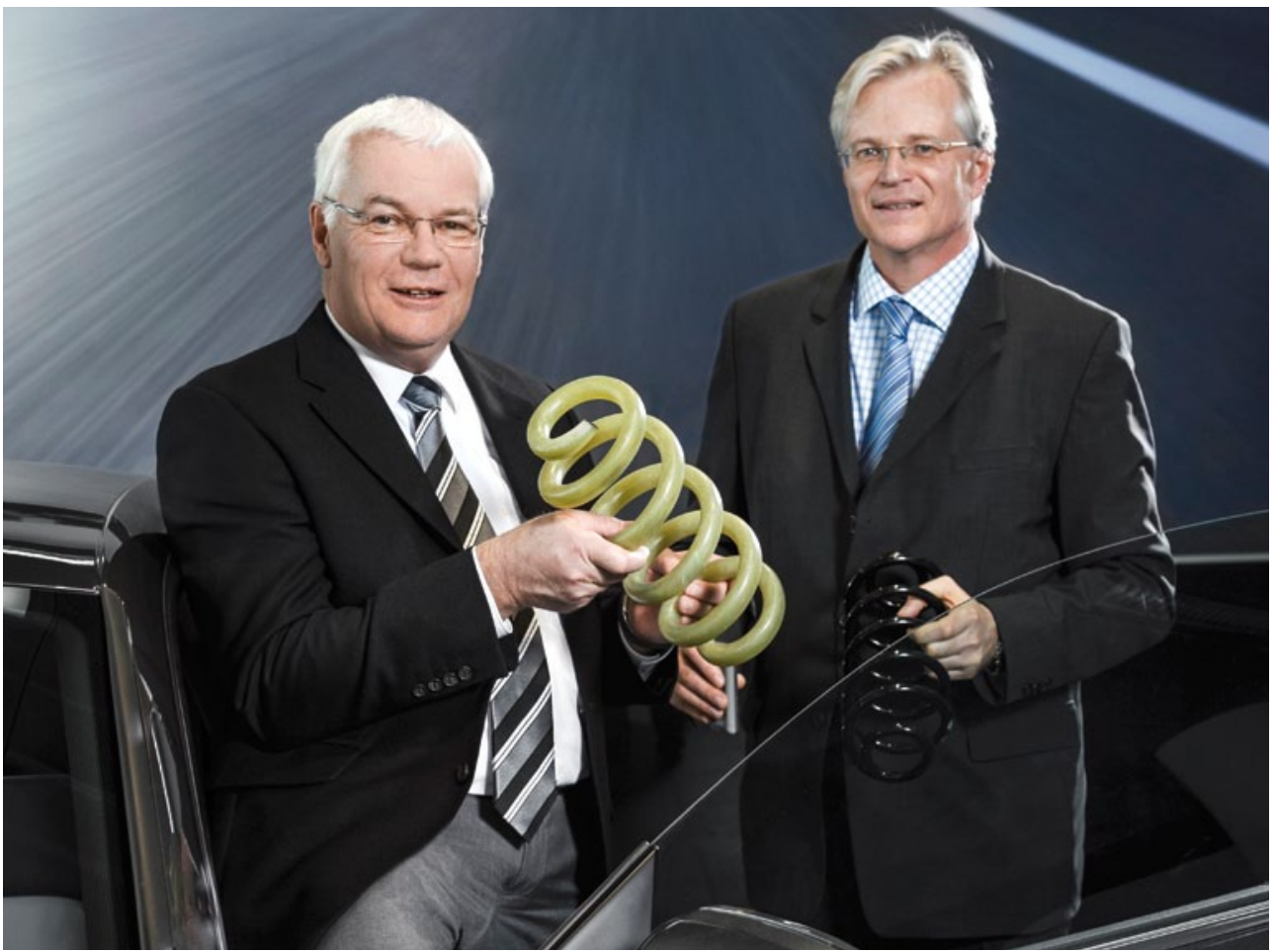

Michael Dick erläutert anschaulich die Möglichkeiten des Leichtbaus und kommt ins Schwärmen beim Vergleich einer herkömmlichen Stahlfeder mit einer Version aus GFK, die über dieselbe Funktion verfügt, aber rund 40 Prozent weniger Gewicht auf die Waage bringt. „Das ist ein sehr schönes Vorentwicklungsprojekt von uns, das zeigt, wie wir Leichtbau auch versteckt in der Auto-Unterwäsche kreativ vorantreiben. Wir werden dieses Thema in der Serie ausrollen."

BILD @ Audi

\section{„EIN STARKER CHARAKTER“}

Wer den heute 60-jährigen Michael Dick trifft, spricht mit einem begeisterten Techniker. Und diese Technikbegeisterung macht sich überall bemerkbar: In seinem Büro im Audi-Entwicklungsareal blitzen Motorsportutensilien - vom Leichtmetallrad bis zum Pokal. In seiner Garage warten Youngtimer vom ersten Audi 80 bis zum Porsche 911 (Typ 993). Der studierte Maschinenbauer schmunzelt, wenn er von seinem ersten Auto, einem Fiat 850 Sport Coupé, erzählt. Schön sei er gewesen und für einen Heckmotorwagen für die damalige Zeit sehr gut zu fahren. „Aber eben kein Vergleich zu dem, wo wir heute stehen“. Ästhetisch und dynamisch, aus der Sicht von Michael Dick verkörpert Audi diese Eigenschaften inzwischen wie keine andere Marke.

\section{„WIR TREIBEN UNS IMMER WIEDER ZU HÖCHSTLEISTUNGEN“}

Seit Januar 2007 ist Dick Vorstand für den Geschäftsbereich Technische Entwicklung der Audi AG. Und dass er an dieser Stelle richtig ist, sieht man nicht bloß am Erfolg der Fahrzeuge der Marke mit den vier Ringen, sondern auch an der Art, wie technische Lösungen kreiert werden.

Wenn Michael Dick erzählt, vergeht die Zeit schnell. Was seiner Meinung nach den Erfolg bestimmt? Seine Antwort: „Ein starker Charakter.“ Ein Beispiel? „Der Modulgedanke, der uns ganz neue Freiheiten gibt. Wie beim Modularen Längsbaukasten, auf dessen Nachfolgegeneration dem MLB evo ab 2014/2015 die A4-Familie mit A5 und Q5 bis hin zum Q7 mit dessen Konzernderivaten aufbauen wird. Wir werden beispielsweise den nächsten Q7 über 300 Kilogramm leichter machen können."

\section{„CFK NUTZEN WIR DORT, WO ES SINNVOLL IST“}

Gewicht ist ein Thema, das dem begeisterten Motorradfahrer am Herzen liegt. „Das richtige Material in der richtigen Spezifikation am richtigen Platz“, sagt er. Daraus ergibt sich zwangsläufig ein weites Anwendungsspektrum. „Wir verwenden CFK dort, wo es für uns Sinn macht, und dies ist nicht in der Großserie wie A3, A4 oder A6. Sehr wohl aber bei den spitz positionierten Modellen unserer Tochtermarke Lamborghini. Oder bei einem RS3 oder einem R8 GT“, meint er zur CFK-Euphorie. Dass er weiter denkt, wird bei Themen wie Energiebilanz, Kosten oder Recycling klar. „Bei Klein- und Kleinstserien ist die Entscheidungsgrundlage eine ganz andere als bei Großserienanwendungen. Beim R8-Nachfolger verwenden wir neben Aluminium auch CFK in größerem Umfang. So senken wir das Zellengewicht auf unter 200 Kilogramm bei einer 40 Prozent höheren Steifigkeit. Das Rückgrat wollen wir in CFK gestalten und gewährleisten dabei volle Reparaturfähigkeit.“

Roland Schede 